\title{
STUDI DESKRIPTIF KADAR DEBU UDARA PADA PENGGILINGAN PADI DAN JAGUNG “SRI REJEKI” DESA BOJONGSARI KECAMATAN BOJONGSARI KABUPATEN PURBALINGGA TAHUN 2016
}

\author{
Alin Andiningtyas ${ }^{1)}$, Susiyanti ${ }^{2)}$ \\ Jurusan Kesehatan Lingkungan, Politeknik Kesehatan Kemenkes Semarang, \\ Jl. Raya Baturaden KM 12 Purwokerto, Indonesia
}

\begin{abstract}
Abstrak
Pencemaran udara merupakan keadaan tercemarnya udara atmosfer oleh suatu sumber, baik melalui aktifitas manusia maupun alamiah dengan dibebaskannya satu beberapa bahan zat-zat dalam kualitas maupun batas waktu tertentu yang secara karakteristik memiliki kecenderungan menimbulkan ketimpangan susunan atmosfer secara ekologi. Pencemaran udara yang terjadi saat ini sudah menjadi masalah yang serius, dengan akibat yang sangat merugikan bagi lingkungan. Tujuan penelitian ini adalah untuk mengetahui tingkat kadar debu udara pada penggilingan padi dan jagung "Sri Rejeki". Metode penelitian ini yaitu menganalisis secara deskriptif dengan menggunakan pendekatan observasional untuk membuat gambaran tentang kadar debu pada penggilingan padi dan jagung "Sri Rejeki" Bojongsari pada saat pengukuran. Hasil penelitian didapat dengan cara pengukuran kadar debu udara menggunakan alat pengukur EPAM (Environmental Prticulate Air Monitoring 5000), jenis pengukuran adalah debu total dengan durasi pengukuran selama 15 menit dalam 1 titik pengulangan 3 hari. Pengukuran dilakukan pada 1 titik selama 3 hari didapatkan hasil kadar debu rata-rata sebesar 586,528mg $/ \mathrm{m}^{3}$. Standar yang digunakan KEPMENKES RI Nomor 1405/MENKES/SK/XI/2002 tentang Persyaratan Kesehatan Lingkungan Kerja Perkantoran dan Industri. Simpulan dari penelitian ini adalah kadar debu udara pada ruang produksi penggilingan padi dan jagung "Sri Rejeki" sebesar 586,528 mg/ m². Apabila dibandingkan dengan baku mutu yang ada, maka kadar debu di penggilingan padi dan jagung "Sri Rejeki" diatas Nilai Ambang Batas yang ditetapkan. Pengelola atau pemilik penggilingan padi dan jagung "Sri Rejeki" sebaiknya melakukan perawatan dan pemeliharaan mesin untuk mengurangi kadar debu dari hasil produksi, pada ruang produksi sebaiknya dilengkapi dengan alat scrubbing dan blower (penyedot debu),dan pengelola atau pemilik penggilingan padi sebaiknya menyediakan masker.
\end{abstract}

Kata kunci : Penggilingan padi dan jagung, Kadar Debu Udara

\section{PENDAhuluan}

Sumber pencemaran udara dapat berasal dari berbagai kegiatan antara lain industri, transportasi, dan perumahan. Berbagai kegiatan tersebut merupakan kontribusi terbesar dari pencemar udara yang dibuang ke udara bebas. Sumber pencemaran udara juga dapat disebabkan oleh berbagai kegiatan alam, seperti kebakaran hutan, gunung meletus, gas alam beracun dan lain-lain. Dampak dari pencemaran udara dapat menyebabkan penurunan kualitas udara, yang berdampak negatif terhadap kesehatan paru-paru. Udara sebagai media lingkungan yang merupakan kebutuhan dasar seseorang perlu mendapatkan perhatian yang serius.

Partikel debu selain memiliki dampak terhadap kesehatan juga dapat menyebabkan gangguan pada kesehatan manusia, seperti timbulnya iritasi pada mata, alergi, gangguan pernafasan dan kanker pada paru-paru. Efek debu terhadap kesehatan sangat tergantung pada : solubity (mudah larut), komposisi kimia, konsentrasi debu, dan ukuran partikel debu.

\section{METODE PENELITIAN}

Penelitian ini dilaksanakan di Penggilingan Padi dan Jagung “Sri Rejeki” Desa Bojongsari, Kecamatan Bojongsari, Kabupaten Purbalingga.

1) Email : alinandiningtyas69@yahoo.com

2) Email : dolphin_fatih_a@yahoo.com
Subyek penelitian yaitu kadar debu lingkungan kerja dengan sampel 1 titik dalam 3 hari pengukuran pada penggilingan padi dan jagung "Sri Rejeki" di Desa Bojongsari, Kecamatan Bojongsari, Kabupaten Purbalingga. Cara pengumpulan data yaitu berupa :

Pengumpulan data dengan cara mengukur kadar debu menggunakan alat EPAM 5000, dan mengukur parameter fisik udara meliputi : suhu menggunakan thermometer, kelembaban hygrometer, kecepatan angin anemometer dan arah angin kompas dan asap.

\section{III.HASIL DAN PEMBAHASAN}

\section{Data Umum}

Penggilingan Padi dan Jagung "Sri Rejeki” adalah salah satu penggilingan padi yang bergerak dibidang produksi beras di desa Bojongsari, Purbalingga yang didirikan pada tahun 2009 oleh Bp. Rianto. Berdiri diatas tanah seluas $1.260 \mathrm{~m}^{3}$, penggilingan padi ini merupakan sebuah penggilingan yang bergerak dalam bidang usaha produksi beras sebagai produksi utama. Penggilingan Padi dan Jagung "Sri Rejeki" sebagai penggilingan padi yang mengolah hasil pertanian khususnya padi menghasilkan produksi beras primer. Padi diproses dari gabah sampai menjadi beras dengan 
dua buah mesin mesin ricemill. Kapasitas produksi tiap hari mencapai 10 ton/ hari.

Bagian antara proses produksi dengan penyimpanan bahan baku dan beras jadi tidak mempunyai dinding pembatas, sehingga antar proses produksi dan gudang dalam satu ruangan, hasil dari proses produksi adalah debu, debu akan dengan mudah menyebar dengan hembusan angin karena ruangan produksi yang tidak sehat.

Ruangan produksi tidak memiliki ventilasi yang cukup, hanya lubang kecil di sebelah kanan kiri dan belakang dinding yang menyebabkan debu tidak dapat keluar ruangan sehingga, mengendap di ruang produksi.

Penggilingan Padi dan Jagung "Sri Rejeki" tepatnya berlokasi di Jl. Raya Bojongsari, Kec. Bojongsari, Kab. Purbalingga. Penentuan lokasi penggilingan padi mempunyai tujuan agar penggilingan padi dapat mempertahankan kontinuitas usahanya dalam jangka panjang, selain itu juga agar semua aktivitas perusahaan dapat berjalan lancar dalam mencapai tujuan.

\section{Data Khusus}

Pelaksanaan penelitian di Penggilingan Padi dan Jagung “Sri Rejeki” Desa Bojongsari, Kecamatan Bojongsari, Kabupaten Purbalingga selama tiga hari dalam satu titik pengukuran, penelitian didapatkan data yang berupa hasil pengukuran kadar debu, pengukuran suhu, pengukuran kelembaban, pengukuran kecepatan angin dan arah angin.

a. Kadar debu

Berdasarkan dari hasil pengukuran yang telah dilakukan di Penggilingan Padi dan Jagung "Sri Rejeki” didapatkan hasil pengukuran debu pada bagian produksi sebagai berikut :

Tabel 4.1 Hasil Pengukuran Kadar Debu di Bagian Produksi Penggilingan Padi dan Jagung "Sri Rejeki” di Desa Bojongsari Kecamatan Bojongsari Kabupaten Purbalingga.

\begin{tabular}{ccccc}
\hline No & Tanggal & $\begin{array}{c}\text { Hasil } \\
\left(\mathbf{m g} / \mathbf{m}^{3}\right)\end{array}$ & $\begin{array}{c}\text { Standar } \\
\mathbf{N A B} \\
\left(\mathbf{m g} / \mathbf{m}^{3}\right)\end{array}$ & $\begin{array}{c}\text { Kesimpu- } \\
\text { lan }\end{array}$ \\
\hline 1. 7 Juni 2016 & 577,984 & 10 & $\begin{array}{c}\text { Melebihi } \\
\text { NAB }\end{array}$ \\
\hline 2. 3 Juni 2016 & 547,008 & 10 & $\begin{array}{c}\text { Melebihi } \\
\text { NAB }\end{array}$ \\
\hline 3. 10 Juni 2016 & 634,592 & 10 & $\begin{array}{c}\text { Melebihi } \\
\text { NAB }\end{array}$ \\
\hline & Rata-rata & 586,528 & 10 & $\begin{array}{c}\text { Melebihi } \\
\text { NAB }\end{array}$ \\
\hline
\end{tabular}

Berdasarkan table 4.1 di atas hasil pengukuran kadar debu selama 3 hari sampel bagian produksi didapatkan hasil melebihi nilai ambang batas (NAB) yang di tetapkan dengan rata-rata kadar debu $586,528 \mathrm{mg} / \mathrm{m}^{3}$.

b. Suhu

Berdasarkan dari hasil pengukuran yang telah dilakukan di Penggilingan Padi dan Jagung "Sri
Rejeki” didapatkan hasil pengukuran suhu pada bagian produksi sebagai berikut :

Tabel 4.2 Hasil Pengukuran Suhu di Bagian Produksi Penggilingan Padi dan Jagung "Sri Rejeki” di Desa Bojongsari Kecamatan Bojongsari Kabupaten Purbalingga.

\begin{tabular}{ccccc}
\hline No & Tanggal & $\begin{array}{c}\text { Hasil } \\
\left({ }^{\circ} \mathbf{C}\right)\end{array}$ & $\begin{array}{c}\text { Standar } \\
\left({ }^{\circ} \mathbf{C}\right)\end{array}$ & Kesimpulan \\
\hline 1 & 7 Juni 2016 & 30 & $18-30$ & Cukup \\
\hline 2 & 8 Juni 2016 & 28 & $18-30$ & Cukup \\
\hline 3 & 10 Juni 2016 & 30 & $18-30$ & Cukup \\
\hline & Rata-rata & 29,33 & $18-30$ & Cukup \\
\hline
\end{tabular}

Berdasarkan tabel 4.2 diatas hasil pengukuran suhu selama 3 hari sampel bagian produksi didapatkan hasil memenuhi syarat $18-30^{\circ} \mathrm{C}$, dengan suhu rata-rata $29,33{ }^{\circ} \mathrm{C}$.

c. Kelembaban

Berdasarkan dari hasil pengukuran yang telah dilakukan di Penggilingan Padi dan Jagung "Sri Rejeki” didapatkan hasil pengukuran kelembaban pada bagian produksi sebagai berikut :

Tabel 4.3 Hasil Pengukuran Kelembaban di Bagian Produksi Penggilingan Padi dan Jagung "Sri Rejeki" di Desa Bojongsari Kecamatan Bojongsari Kabupaten Purbalingga.

\begin{tabular}{ccccc}
\hline No & Tanggal & $\begin{array}{c}\text { Hasil } \\
(\mathbf{\%})\end{array}$ & $\begin{array}{c}\text { Standar } \\
\mathbf{( \% )}\end{array}$ & Kesimpulan \\
\hline 1 & 7 Juni 2016 & 91 & $65-95$ & Cukup \\
\hline 2 & 3 Juni 2016 & 91 & $65-95$ & Cukup \\
\hline 3 & 10 Juni 2016 & 91 & $65-95$ & Cukup \\
\hline & Rata-rata & 91 & $65-95$ & Cukup
\end{tabular}

Berdasarkan tabel 4.3 diatas hasil pengukuran kelembaban selama 3 hari bagian produksi didapatkan hasil memenuhi syarat 65-95\%, dengan kelembaban rata-rata 91\%.

d. Kecepatan angin

Berdasarkan dari hasil pengukuran yang telah dilakukan di Penggilingan Padi dan Jagung "Sri Rejeki” didapatkan hasil pengukuran kecepatan angin pada bagian produksi sebagai berikut :

Tabel 4.4 Hasil Pengukuran Kecepatan angin di Bagian Produksi Penggilingan Padi dan Jagung "Sri Rejeki" di Desa Bojongsari Kecamatan Bojongsari Kabupaten Purbalingga.

\begin{tabular}{ccccc}
\hline No. & Tanggal & $\begin{array}{c}\text { Kecep- } \\
\text { atan } \\
\text { angin } \\
(\mathbf{m} / \mathbf{s})\end{array}$ & Standar & $\begin{array}{c}\text { Kesimpu- } \\
\text { lan }\end{array}$ \\
\hline 1 & 7 Juni 2016 & 0,2 & $0,15-0,25$ & Cukup \\
\hline 2 & 8 Juni 2016 & 0,1 & $0,15-0,25$ & Cukup \\
\hline 3 & 10 Juni 2016 & 0,2 & $0,15-0,25$ & Cukup \\
\hline & Rata-rata & 0,16 & $0,15-0,25$ & Cukup \\
\hline
\end{tabular}

Berdasarkan tabel 4.4 diatas hasil pengukuran kecepatan angin selama 3 hari bagian produksi didapatkan hasil memenuhi syarat 0,15-0,25 , dengan kecepatan angin rata-rata 0,16 m/s.

e. Arah angin

Berdasarkan dari hasil pengukuran yang telah dilakukan di Penggilingan Padi dan Jagung "Sri 
Rejeki” didapatkan hasil arah angin pada bagian produksi sebagai berikut :

Tabel 4.5 Hasil Pengukuran Arah angin di Bagian Produksi Penggilingan Padi dan Jagung "SriRejeki" di Desa Bojongsari Kecamatan Bojongsari Kabupaten Purbalingga.

\begin{tabular}{ccc}
\hline No & \multicolumn{1}{c}{ Tanggal } & Arah Angin \\
\hline 1 & 7 Juni 2016 & Selatan \\
\hline 2 & 8 Juni 2016 & Timur \\
\hline 3 & 10 Juni 2016 & Barat \\
\hline
\end{tabular}

Berdasarkan tabel 4.5 diatas hasil pengukuran arah angin selama 3 hari sampel bagian produksi didapatkan hasil arah angin berbeda-beda arah.

\section{IV.KESIMPULAN}

Berdasarkan hasil dan pembahasan tentang studi deskriptif kadar debu udara pada penggilingan padi dan jagung "Sri Rejeki” yang telah diuraikan dapat diambil simpulan sebagai berikut :

a. Hasil Pengukuran Kadar Debu didapat hasil kadar debu 586,528 mg/m³ melebihi Nilai Ambang Batas (NAB) yang di tentukan yaitu $10 \mathrm{mg} / \mathrm{m}^{3}$.

b. Hasil Pengukuran suhu didapatkan hasil suhu $29,33^{\circ} \mathrm{C}$ dibawah standar yaitu $18-30^{\circ} \mathrm{C}$.

c. Hasil Pengukuran Kelembaban didapat hasil kelembaban 91\% dibawah standar yaitu 65-95\%.

d. Hasil Pengukuran Kecepatan angin didapat hasil $0,16 \mathrm{~m} / \mathrm{s}$ dibawah standar $0,15-0,25 \mathrm{~m} / \mathrm{s}$.

e. Hasil Pengukuran Arah angin berbeda-beda yaitu:

- Tanggal 7 Juni $2016=$ Selatan

- Tanggal 8 Juni $2016=$ Timur

- Tanggal 10 Juni 2016 = Barat

\section{DAFTAR PUSTAKA}

Al. Slamet Riyadi, 1982, Pencemaran Udara, Surabaya : Usaha Nasional

A. Tresna Sastrawijaya, 2000, Pencemaran Lingkungan, Jakarta : Rineka Cipta
H.J Mukono, 2008, Pencemaran Udara dan Pengaruhnya Terhadap Gangguan Saluran Pernapasan, Surabaya : Airlangga

http://hengkihermawan93.blogspot.co.id/2013/12/mak alah-penggiling padi.html?=i, Diakses pada tanggal 20 Januari 2016 pukul 20.00

http://idhamgufan.blogspot.co.id/2012/03/proses-daripadi-bisa-menjadiberas.html?m=i, Diakses pada tanggal 20 Januari 2016 pukul 21.21

http://lodita.wordpress.com/tag/undang-undang-no-1tahun-1970-tentang-keselamatan-kerja/,

Diakses pada tanggal 23 Januari 2016 pukul 20.45

Keputusan Menteri Kesehatan Nomor 1405/ Menkes/SK/XI/2002 tentang Persyaratan Kesehatan Lingkungan Kerja Perkantoran Industri

Menurut Dinas Tenaga Kerja dan Transmigrasi Prov. DIY Balai Hyperkes dan Keselamatan Kerja (2009)

Moestikahadi Soedomo, 2001, Pencemaran Udara, Bandung : ITB

Peraturan Pemerintah RI No 41 Tahun 1999, Pengendalian Pencemaran Udara

, RI No 41 Tahun 1999. Baku Mutu Udara Ambient Nasional

Srikandi Fardiaz, 2003, Polusi Air Dan Udara, Yogyakarta : Kanisius

Tri Cahyono, 2014, Pedoman Penulisan Proposal Penelitian Dan Karya Tulis Ilmiah/Skripsi 